University of Louisville

ThinkIR: The University of Louisville's Institutional Repository

$5-2014$

\title{
Implementation of an oral health intervention for adults with intellectual and developmental disabilities.
}

\author{
Brigit Rene Zaksek \\ University of Louisville
}

Follow this and additional works at: https://ir.library.louisville.edu/etd

Part of the Oral Biology and Oral Pathology Commons

\section{Recommended Citation}

Zaksek, Brigit Rene, "Implementation of an oral health intervention for adults with intellectual and developmental disabilities." (2014). Electronic Theses and Dissertations. Paper 1631.

https://doi.org/10.18297/etd/1631

This Master's Thesis is brought to you for free and open access by ThinkIR: The University of Louisville's Institutional Repository. It has been accepted for inclusion in Electronic Theses and Dissertations by an authorized administrator of ThinkIR: The University of Louisville's Institutional Repository. This title appears here courtesy of the author, who has retained all other copyrights. For more information, please contact thinkir@louisville.edu. 
IMPLEMENTATION OF AN ORAL HEALTH INTERVENTION FOR ADULTS WITH INTELLECTUAL AND DEVELOPMENTAL DISABILITIES

\author{
By \\ Brigit Rene Zaksek \\ B.S., Ohio State University, 1997
}

A Thesis Submitted to the Faculty of the School of Dentistry of the University of Louisville in Partial Fulfillment of Requirements for the Degree of

\author{
Masters of Science
}

Department of Oral Biology

University Of Louisville

Louisville, KY

May 2014 
Copyright 2014 by Brigit Rene Zaksek

All rights reserved 

IMPLEMENTATION OF AN ORAL HEALTH INTERVENTION FOR ADULTS WITH INTELLECTUAL AND DEVELOPMENTAL DISABILITIES

By

Brigit Rene' Zaksek, B.S., Ohio State University

A Thesis Approved on

April 15, 2014

by the following Thesis Committee:

Catherine Binkley, DDS, MSPH, PhD-Thesis Director

Kenneth Chapman, PhD - Committee Member

Robert Staat, PhD - Committee Member 


\section{DEDICATION}

This dissertation is dedicated to my mother

Mrs. Kathleen R. Brown.

She has ALWAYS given me constant encouragement through

my changing educational dreams. 


\title{
ACKNOWLEDGEMENTS
}

\author{
I want to thank my advisor, Dr. Cathy Binkley, for her \\ encouragement and guidance during this process. I appreciate her \\ advice during my many telephone calls and e-mails, both days and \\ nights. Also, I extend thanks to all my friends, family, and coworkers \\ who have listened to my celebrations, rants, and raves through this \\ entire back-to-school process. Thank you for being there when I needed \\ you most.
}




\title{
ABSTRACT \\ IMPLEMENTATION OF AN ORAL HEALTH INTERVENTION FOR ADULTS WITH INTELLECTUAL AND DEVELOPMENTAL DISABILITIES
}

\author{
Brigit R. Zaksek
}

April 15, 2014

Often oral care is overlooked during the daily care of adults with intellectual and developmental disabilities (IDD). Due to the integration of adults with IDD from institutions into group homes and private homes, caregivers need to be taught to implement daily oral hygiene protocols. The purpose of this pilot study, conducted by the University of Louisville and the Pacific Institute for Research and Evaluation, was to develop an oral hygiene plan for adults with IDD residing in group homes in the Louisville, Kentucky area that would ultimately improve their oral health and quality of life.

This thesis focuses on the quality of implementation of the oral health intervention strategy based on the results from the pilot study. Additionally, this thesis sheds light on the level of implementation quality as measured by dosage, fidelity, and caregiver reactions. 
TABLE OF CONTENTS

PAGE

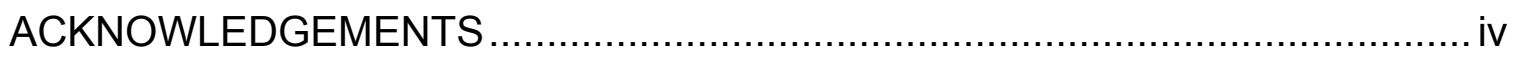

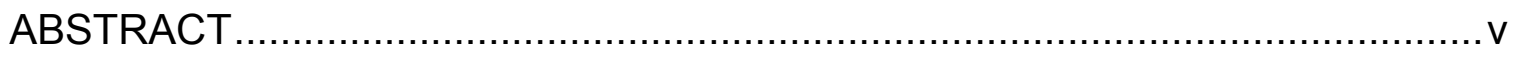

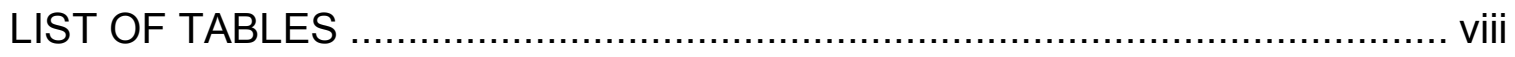

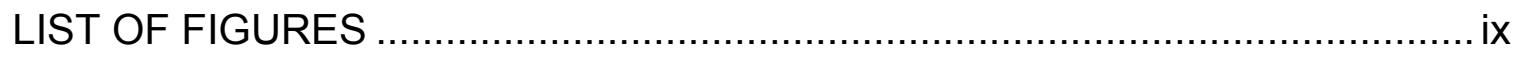

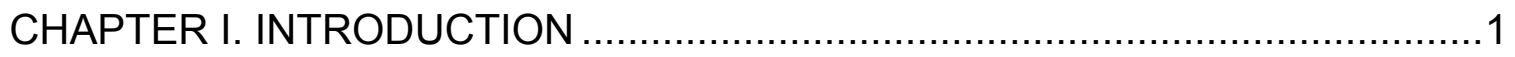

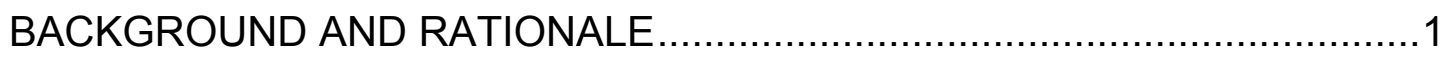

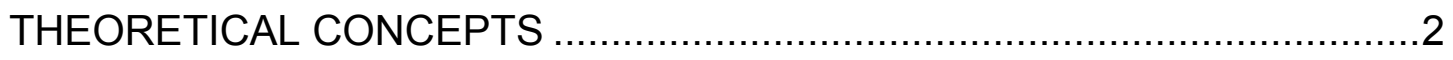

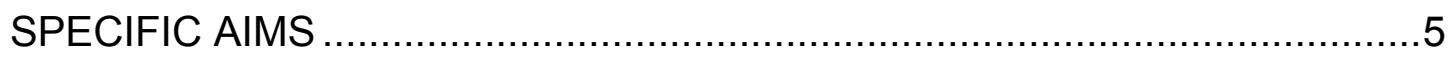

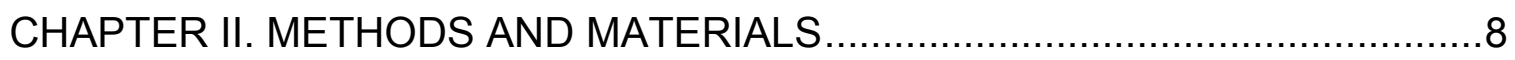

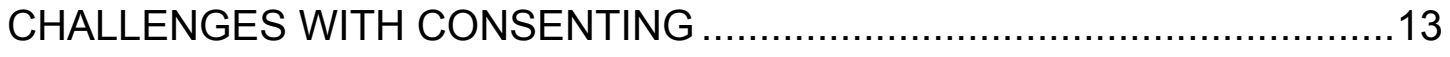

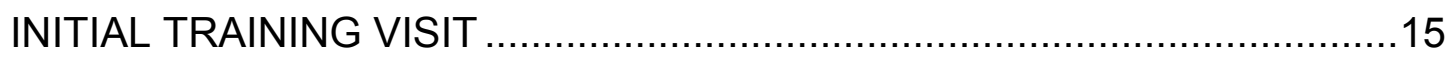

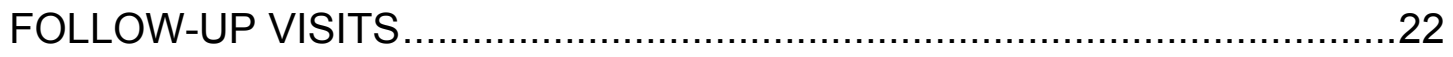

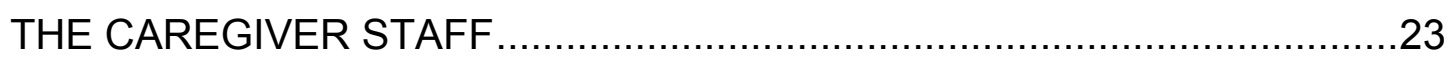

CHALLENGES WITH CAREGIVER STAFF .....................................24

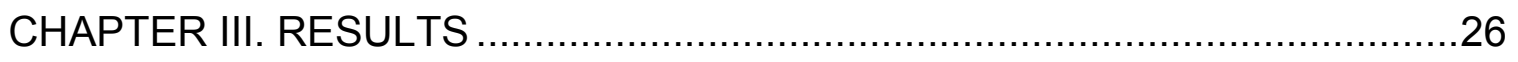

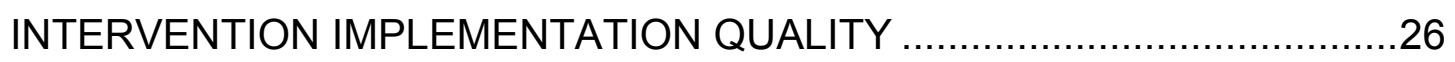

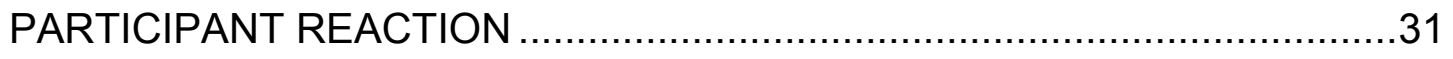

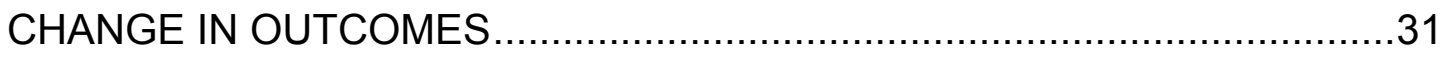




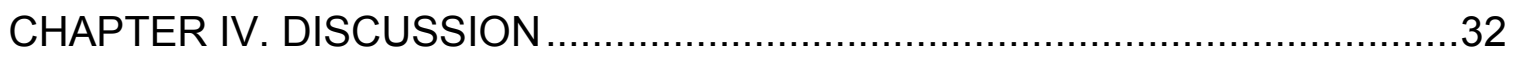

CHAPTER V. SUMMARY AND CONCLUSIONS ......................................41

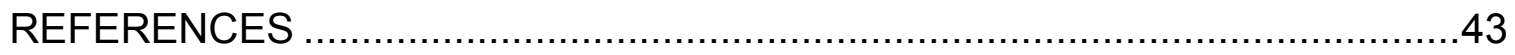

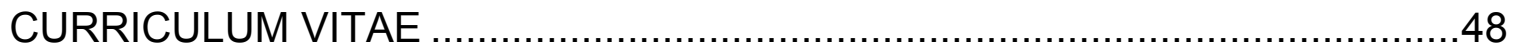




\section{LIST OF TABLES}

$\begin{array}{ll}\text { TABLE } & \text { PAGE }\end{array}$

Table 1. Characteristics of Adults with IDD and Caregivers ...........................10

Table 2. Implementation Quality (Dosage \& Fidelity) by

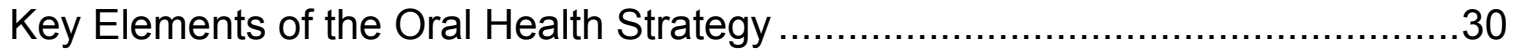

Table 3. Average Caregiver Reaction to Key Elements of the

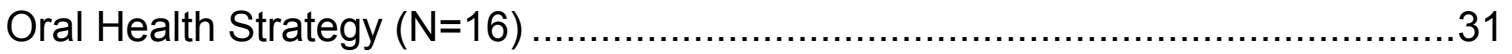




\section{LIST OF FIGURES}

FIGURE $\quad$ PAGE

Figure 1. Conceptual View of an Oral Health Strategy for Adults

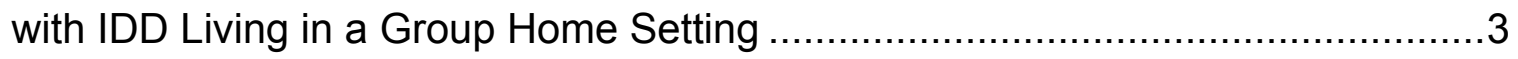




\section{CHAPTER I}

\section{INTRODUCTION}

\section{BACKGROUND AND RATIONALE}

Traditionally, most individuals with moderate to profound intellectual and developmental disabilities (IDD) have been housed in large medical institutions. These facilities had a fully trained medical and dental staff to care for the residents with IDD. In the past decade, an effort has been made to deinstitutionalize these individuals with IDD by moving them to group home settings. This effort has increased their quality of life by integrating them into life's daily routines as non-IDD individuals experience it. However, it has severely limited or totally eliminated their access to dental care.(1)

More than a million individuals with intellectual and/or developmental disabilities live in the United States.(2) Of those adults with IDD, a large portion lives in community settings such as group homes. This population, whether living with family or in a group home, receives less preventative medical care than individuals with IDD living in institutional settings.(3) Moreover, they are less likely to receive regular dental care.(4) Adults with IDD are more likely to have poor oral hygiene, increased decay, and periodontal disease than the general population.(5-8) This is partly because many adults with IDD are insured by 
Medicaid, not by private insurance companies. Most dentists do not accept Medicaid or are unable to work on patients with IDD, so finding providers is difficult. Some caregivers may have low dental health knowledge and/or may be unable to handle the uncooperative behavior of adults with IDD while administering daily routine oral care. Increased risks of respiratory infections, like aspiration pneumonia, can be linked to the poor oral health of these adults with IDD.(9)

As with some other aspects of their daily life, most special needs individuals cannot fully perform basic dental hygiene on themselves. This inability to care for themselves, coupled with the fact that this population is not typically receiving regular dental hygiene, restorative and/or surgical treatment in a dental office, leads to increased periodontal disease, decay, need for extractions, and respiratory infections.(5-9) Thus, it is imperative that this population has proper dental hygiene care performed on them daily by their caregivers. Preventing or decreasing periodontal disease and decay, as well as other systemic issues, should be a routine standard of care.

\section{THEORETICAL CONCEPTS}

Efforts to develop and evaluate various strategies to improve the oral hygiene and oral health of this vulnerable population have been met with minimal to moderate success.(10-14) None of these interventions used a planning model or a theory-based behavior change intervention for caregivers of adults with IDD. To the best of our knowledge, only a few studies have been conducted on how to use a planning model to improve dental public health $(15,16)$, but these studies 
have not been used to develop a theory-based oral health strategy or an intervention for adults with IDD.

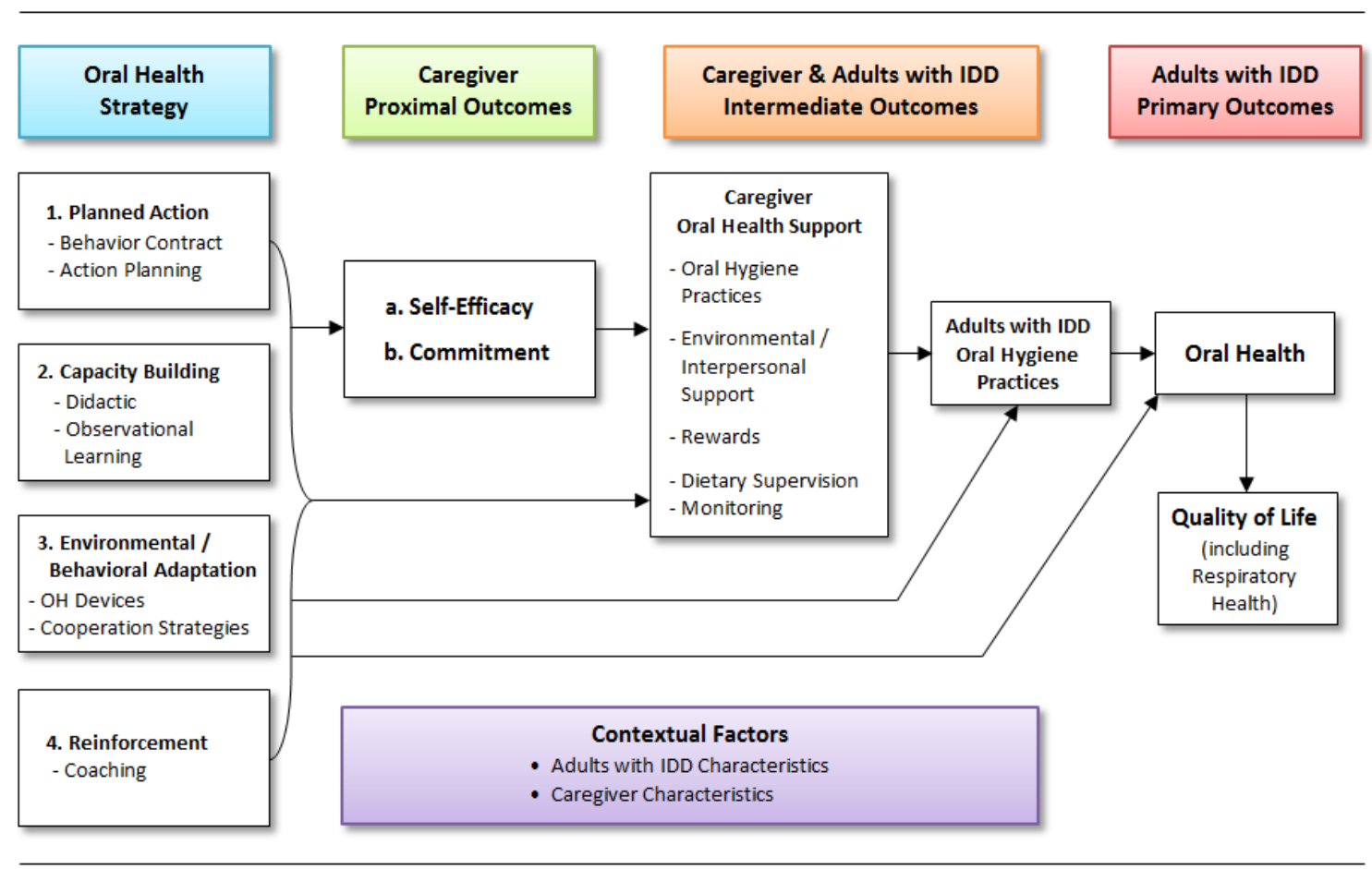

Figure 1.

Conceptual View of an Oral Health Strategy for Adults with IDD Living in a Group Home Setting

The conceptual framework is graphically presented in Figure 1 above. The study used four constructs from two theories—Social Cognitive Theory (SCT) and Health Action Process Approach (HAPA) - to assess their effect as mechanisms of change or mediating variables in the strategy framework: selfefficacy, behavioral capability, and environmental influences from SCT, and outcome expectancies constructs from both SCT and HAPA. I posited links between the determinants of the targeted oral health of an IDD population and 
my theory-based oral health strategy that is described in the following paragraphs.

First, I theorized that if I used a written contract and incentives with the caregivers, rather than just a verbal agreement, their implementation of the intervention would be more successful. The caregivers signed a contract stating they were willing to participate in the study, after which they received the information about their needed involvement. To encourage caregivers' participation, incentives (gift cards) were given at the start and at the completion of the intervention. Dr. Binkley gave each caregiver a "certificate" verifying he or she completed the oral hygiene training, adding to the strength of his or her resume.

Second, I theorized that the use of capacity building would aid the caregiver by providing them with reasons why dental care was important and by giving them techniques to use for each individual. Capacity building incorporates various types of trainings to aid caregivers in performing new dental hygiene regimens for individuals with IDD. I used videos, didactic training, and reinforcement training to help them understand the importance of providing daily dental hygiene to each adult with IDD.

Lastly, I theorized that by using didactic training, I could improve the process of learning new concepts and techniques. I completed hands-on initial and follow-up trainings to clarify any issues caregivers had with the technique, individual resistance, and the setting of new and higher goals toward better dental hygiene. The initial training consisted of an introduction to dental aids, 
such as the mouth prop, Collis brush, disclosing solutions (tablet, liquid and cotton tip applicator), flavored toothpastes, and floss picks, which were demonstrated on a manikin or Dentoform. The caregivers were also shown basic brushing and flossing techniques on the Dentoform. They could touch all the dental aids to see how they were to work in the mouths of adults with IDD.

I also showed the caregivers how to modify the dental tools for easier individual use. One such modification was putting the base of a toothbrush through a tennis ball or foam bicycle handle to allow for a larger grip for adults with manual dexterity issues. Another modification was to perform oral hygiene somewhere other than the bathroom. Due to lack of space, it was sometimes easier to perform dental hygiene at the kitchen table, while watching television, or while in the bedroom with the patient lying in bed.

Each of the two follow-up training sessions was spaced 2 weeks apart. I tried to perform dental hygiene on adults with IDD to address any specific behavioral issues or any technique problems the caregivers were having with each resident. Hands-on training allowed me to reinforce and monitor the dental health plan for each individual. This, in theory, allowed me to set new written goals for the dental health care plan at each training visit.

\section{SPECIFIC AIMS}

The specific aims and research questions of the entire pilot test of the intervention follow: 
Aim 1. Demonstrate the efficacy of an oral health strategy to improve the oral health, oral-health-related quality of life, and respiratory status of adults with IDD.

1.1 What are the changes in the distal outcomes (adult with IDD oral health and oral health quality of life) that might be attributable to the oral health strategy?

1.2 What are the changes in intermediate outcomes (adult with IDD oral hygiene practices) that might be attributable to the oral health strategy?

1.3 What are the changes in intermediate outcomes (caregiver oral health support) as measured by oral hygiene supervision, environmental adaption, dietary supervision, and oral health planning and monitoring that might be attributable to the oral health strategy?

1.4 What are the changes in proximal outcomes (caregiver self-efficacy and commitment) that might be attributable to the oral health strategy?

Aim 2. Assess quality of implementation of the oral health strategy and its association with the study outcomes.

2.1 What is the level of implementation quality as measured by dosage, fidelity, and caregiver reactions?

My role in the pilot test was as the interventionist who delivered the oral health strategy to the study participants. For my Master's thesis, I will focus on the following specific aim:

Aim 2. Assess the quality of implementation of the oral health intervention strategy. 
2.1 What is the level of implementation quality as measured by dosage, fidelity, and caregiver reactions? 


\section{CHAPTER II \\ METHODS AND MATERIALS}

This chapter describes the study methods and the challenges I encountered in consenting the study participants and in implementing the intervention. The pilot study entailed conducting a preliminary assessment of implementation quality and change in outcomes specified in our conceptual framework (Figure 1) using a pre-post intervention design only. Initially, I obtained administrative agreements from one organization that provides residential services to adults with IDD in the Louisville, Kentucky, area. The study recruited 47 caregivers and 3 declined to participate, and I recruited 42 adults with IDD and 11 parents/legally authorized representatives (LARs) declined to provide consent. The consent rate was $94 \%$ for caregivers and $74 \%$ for adults with IDD, with $100 \%$ of state guardians providing consent and $50 \%$ of parents/LARs providing consent. Of the 44 caregivers who consented, 23 failed the screening criteria (left employment, group home not in study, etc.), and of the 31 consented adults with a disability, 6 failed the screening criteria. The final study participants, 21 caregivers and 25 adults with IDD, worked and lived in 11 group homes. 
The target population selected was persons with IDD because they have poor oral hygiene and frequently do not receive routine dental care. $(3,4)$ The sample for this nonrandomized pilot test was drawn from a population of persons with IDD who reside in community group home settings in the state of Kentucky who:

- Have had a diagnosis of mild to profound intellectual and/or developmental disability;

- Are at least 18 years of age;

- Live in community group homes; and

- Have agreed, or a parent or LAR has agreed, to provide consent for the adult with IDD to participate in the study.

Before enrolling caregivers and adults with IDD, consent was obtained to participate: for caregivers, their own consent; for adults with IDD, their own consent or their parents'/guardians' consent. The caregivers completed surveys at baseline that gathered their health history information, basic demographic information (age, race, sex, income levels, education levels, etc.), and dental health background and dental health knowledge. This survey provided me with a profile of the typical caregiver who was caring for the adults with IDD. It also provided information such as a caregiver's dental fears or bad experiences, if any, that might have kept them from seeking their own dental treatment from a dental professional. If a negative dental history for the caregiver was present, would it contribute or hamper his or her ability to care for the dental health needs of their 
adult with IDD? The characteristics of the adults with IDD and the caregivers are presented in Table 1.

Table 1.

Characteristics of Adults with IDD and Caregivers

\section{Average}

\section{Adults with IDD (Residents)}

Level of Disability

Mild

$29 \%$

Moderate

$39 \%$

Severe

$21 \%$

Age

45

Gender - male

$62 \%$

Race - White

$68 \%$

No. of Teeth

No. of Carious/Fractured Teeth

No. of Filled Teeth

Dental Visits in Past Year

2.4

Number of Months since Last Dental Visit

4.5

\section{Caregivers}

Age

Gender - male $29 \%$

Race - White $24 \%$

Education

Less than high school

$19 \%$

High school

$33 \%$

Associate's degree $38 \%$

Bachelor's degree $10 \%$

No. Years Worked with Disabled Persons 4.6

Note: Resident sample $=21$; Caregiver sample $=16$. 
The following forms were used to collect data to assess implementation quality:

- Caregiver Didactic and Demonstration Training Forms - This process form tracked intervention fidelity of the initial didactic and demonstration training provided by me at the start of the study. I completed the form and verified which caregivers participated in the training and to what extent (complete, partial, no participation), whether specific components of the training session were completely covered, partially covered, or not covered, and also asked whether adaptations to the planned implementation were made and reasons why. Initial training components covered on the form included: the behavioral contract, oral hygiene training, dental devices, resident cooperation strategies, dietary supervision, and planning and monitoring.

- Coaching Process Form [Dental Hygienist] - This process form tracked intervention fidelity of the coaching sessions I provided. I completed the form and documented which caregivers participated in the session and to what extent (complete, partial, no participation), whether specific components of the coaching session were completely covered, partially covered, or not covered, and also asked whether adaptations to the planned implementation were made and reasons why. Coaching components covered on the form included: overview/evaluation of resident oral hygiene practices and plaque scores, dental devices, 
resident cooperation strategies, dietary supervision, and planning and monitoring.

- Caregiver Reactions Questionnaire - Caregivers were asked to complete a reaction form immediately following the initial training that included questions about whether the behavioral contract was clear, the quality of the initial training on key training objectives (e.g., how to detect plaque, proper oral hygiene practices, importance of monitoring, etc.), the quality of the training videos, the quality of the demonstrations, and the quality of the hands-on experiences. In addition, caregivers were asked about their reactions to the coaching sessions and the intervention as a whole in the Post-Intervention Caregiver Questionnaire. Survey measures included: the helpfulness of the coaching sessions, their satisfaction with me as the trainer and training in helping them and their residents improve oral hygiene behaviors, and how the new practices they learned fit into their daily schedules.

- Training Video Process Observation Forms - This form was completed by the evaluators (at PIRE) while watching videos of the trainings. I collected video during the trainings and coaching sessions. The coding form collected information including: which caregivers participated in the training and to what extent (complete, partial, no participation), whether specific components of the training session were completely covered, partially covered, or not covered, and also asked whether 
adaptations to the planned implementation were made and reasons why.

\section{CHALLENGES WITH CONSENTING}

Having support from the organization where the study is conducted helps unify the staff and aids in caregiver adherence to new protocols. A key to demonstrating strong support is having well written protocols for oral hygiene within the facility and group meetings and training.(37) These key elements were missing from our pilot study from the start. I had solid, positive feedback of how beneficial this dental protocol would be when it was presented to the upper management. I felt I also had a strong contact and supporter of this study in the head supervisor. He assured me the caregivers, parents/guardians, and residents at each house would receive information about the study and that they would be expecting me to contact them. This "memorandum" was never sent, which posed cascading problems with obtaining consent from the start of the pilot study. Correspondence between caregivers and the corporate office was typically done via facsimile.

The consenting process was designed to take two months, but it actually took six months. This was due to the following:

- Consent forms to parents/guardians were sent by postal mail to their homes, to be completed to give permission for their children or ward with IDD to participate in the study. However, because this organization did not alert the parents/guardians about the study, I did not receive a large return on consent forms. So, each parent/guardian 
had to be contacted directly to explain who I was, the details of the study, and what I was asking of the adult residents.

- Consent forms to adults with IDD who were their own legal guardians were sent to their respective group homes. I was not informed that postal mail is not sent to the residents' group homes, but to the corporate office. Again, this resulted in having to obtain, in person, a consent form from each adult with IDD.

- Consent forms to caregivers were posted to each group home. Just as with the residents, the mail was not sent to the group home. Any mail received is automatically forwarded to the corporate office. The caregivers never check their mail, as they do not receive mail at the group home. As with the other consents, I had to personally contact each caregiver.

Obtaining the consent from caregivers, even in person, was labor intensive for many reasons. One hurdle was that most of them are from other countries; thus, some are not proficient in English. Further, most were very apprehensive about signing any paperwork I had for them. They questioned every item on the consent form before agreeing to sign. Many caregivers asked me to not share their information with their employer. They were assured numerous times that I would not share their information with their employer or anyone else. I had to explain that the Health Insurance Portability and Accountability Act (HIPPA) explicitly states I was bound by law to not share their 
information beyond our staff for the study. I also assured them that they would not be viewed either negatively or positively for their participation in the study. Another roadblock of consenting was that the houses were staffed from around 4 p.m. to midnight and midnight to 8 a.m. The adults with IDD typically went to a "day program" from around 7 a.m. to 4 p.m., and during those times, the group home was not staffed. There were typically two to three caregivers per home, depending on the severity of the disabilities of the residents. The times and shifts the caregivers worked made it difficult to schedule a meeting to discuss the study.

\section{INITIAL TRAINING VISIT}

The initial training visits were scheduled on a day when all caregivers from a particular group home could be present for training. The initial training was about 2 hours. It involved videos, didactic training with oral hygiene instruction on a typodont and on each resident, modifications of dental products, behavioral techniques, rewards, positive reinforcement, and implementation of a written Daily Oral Hygiene Plan for each resident. Adults with IDD also received disclosing solution, toothbrushes, toothpaste, and floss picks. At the end of the training, all caregivers' questions were answered and clarified.

Each adult with IDD received a folder for their Daily Oral Hygiene Plan and a checklist for the caregivers to complete. I also left electronic tablets at each group home so the checklist for each adult with IDD could be completed online. I had both paper and computer options, as some caregivers were not computer literate. The checklist was preloaded on the tablet, so all the caregiver had to do was obtain a wireless connection and enter the information for the Daily Oral 
Hygiene Plan. When completed, it would automatically be saved and data could be retrieved from the tablet by the Pacific Institute for Research and Evaluation (PIRE) research team who were subcontractors to the University of Louisville. There was some trouble with the tablets and the Wi-Fi connection that was rectified by PIRE within the first few weeks.

At first, the Daily Oral Hygiene Plans were completed twice on paper-one copy was left at the group home for the caregivers to reference, and a second copy was given to PIRE for research compilation. After a few visits, I suggested carbon copies be made to eliminate the duplication of work. Implementation of this change expedited the follow-up visits in the following sessions.

The first video I used in the initial training educated the caregivers about plaque composition, reasons for cavities and gum disease, and diet. The video also explained systemic links, such as increased risks of heart disease, stroke, and diabetes complications. I emphasized that proper oral hygiene is necessary not only for mouth health, but also for its link to a myriad of other systemic issues. The video was assembled and narrated by Dr. Cathy Binkley, DMD.

The second video I used was from the University of the Pacific called, "Overcoming Obstacles to Dental Health," $4^{\text {th }}$ Edition.(12) It showed practical application skills that caregivers needed to perform daily dental hygiene on their adults with IDD. The video demonstrated techniques to get around a resistant adult's mood, such as desensitizing and shaping, modifications to dental tools, positive reinforcements, and rewards. These techniques were customized in the 
Daily Oral Hygiene Plan for each adult with IDD based on the issues or concerns expressed by the caregivers.

Desensitizing is a slow introduction to something new to help acclimate the adult with IDD to the new protocols. It allows individuals to become familiar with the new tools or dental aids at their own pace. During the initial training, I suggested that adults with IDD be introduced slowly to a new dental tool, such as letting them hear a new electric toothbrush and even touch it with their hands before performing oral hygiene with it in the mouth. This technique helps with resistance to new and different dental tools and experiences. It also allows for more acceptance of daily oral hygiene by giving an adult with IDD a positive dental hygiene experience with no fear. Further, it minimizes caregivers' stress, as they would not have a battle with performing daily dental hygiene.

Desensitizing is a win-win technique that makes all involved much more open for giving and receiving dental care.

Shaping is introducing something new to an individual and asking them to do just a portion of the task and praising or rewarding them when the task is performed. In each consecutive session, individuals perform an additional step for which they receive praise or a reward. It breaks down the complete hygiene routine into segments, leading to completion of an entire hygiene session. The video stressed the importance of positive reinforcement during the entire dental hygiene session. For example, trainees started by brushing only the "fronts" of the lower arch and were given a reward. The next time, they brushed the "fronts 
and backs" of the lower arch before a reward was given. This step-by-step progression led to completion of the entire oral hygiene task.

The rewards included giving individuals a food or beverage (non-sugar based treats) they liked, time spent doing an activity they enjoyed, or time to listen to music or to watch a television program they enjoyed. One caregiver gave a quarter to each resident for a reward system. He said he did this regularly to gain cooperation when doing other daily tasks, and it was a great motivator. As the caregivers had a stronger relationship and bond with their adults with IDD, I let them establish which ways they could best help motivate each resident to complete daily oral hygiene. This information was included on each Daily Oral Health Plan. One copy was left at the homes, and one copy was sent to PIRE for data compilation.

The content of these videos would be readdressed and reinforced in the hands-on portion of the initial training. The caregivers were first shown proper brushing (manual, Collis, and electric toothbrushes), tongue brushing, and flossing techniques with floss picks. This demonstration stressed to caregivers the daily need to mechanically remove the plaque on the teeth to prevent dental and whole body problems. The Collis toothbrush is a special brush that cleans all surfaces of a tooth at once. It has a short row or two of central bristles down the middle of the brush head. It also has bristles on each side of the brush head, which are very long and curved to allow for gum line brushing on all sides of the tooth simultaneously with the occlusal surfaces. Due to short attention spans of most of the adults with IDD, I recommended the Collis toothbrush for use by the 
caregivers. Using this toothbrush allowed caregivers to "follow-up" and complete brushing quickly and efficiently on their adults with IDD. Most of the caregivers seemed to like the ability to quickly clean all surfaces of the teeth at once.

Each adult with IDD was given a soft manual or electric toothbrush and their choice of flavored toothpaste. The caregivers were given additional dental supplies, including a mouth prop, a Collis toothbrush, floss picks, and enough disclosing solution to last (one for each day) until the next scheduled training. Placing the dental supplies in a baggie labeled with the name of each adult with IDD seemed to be the best way to avoid cross-contamination. The bag of dental supplies was kept in a locked cupboard with each patient's medications and handed out when oral hygiene was performed.

Adults with IDD often have not just mental, but also physical disabilities; thus, it is often necessary to modify typical oral hygiene products to accommodate their specific needs. A common modification shown during training was to widen the handle of a toothbrush with a towel and some tape, a rubber bike handle, or a tennis ball slid over the brush handle. Slight modifications such as these often enable adults with IDD to become more independent with their oral hygiene. I did not have to make modifications for any of the adults with IDD in this particular study. However, I told the caregivers that they might need to use some of these modifications later in their careers.

Flossing is a very difficult process, even for someone without IDD. So, the use of floss sticks, picks, or interdental brushes was necessary to demonstrate to caregivers with this population. Due to the limited manual dexterity of adults with 
IDD, I suggested that the caregivers always help out when flossing to avoid gingival trauma. Due to the poor oral hygiene of the adults with IDD, caregivers were very apprehensive about correctly flossing below the gum line because it caused gingival bleeding. I reinforced the need to thoroughly clean below the gum line to gain gingival health.

I wanted to encourage positive experiences when caregivers performed oral hygiene on the adults with IDD. One suggestion was to perform oral hygiene somewhere other than the bathroom. Some adults with IDD might feel more comfortable in bed, on the couch watching television, or at the dining room table after dinner. These alternative locations were listed on the Daily Oral Hygiene Plan for reference. I encouraged the caregiver to use positive reinforcements during dental hygiene, such as smiles, high fives, and encouraging words. When positive reinforcements are used during the dental hygiene session, it can provide a more a positive experience for both the adult with IDD and the caregiver.

The skills learned during the initial training were then implemented on each adult with IDD in the home. Hands-on training allowed me to modify the delivery for any dental task to improve the experience. I felt real life "practice" dealing with each temperament and mental or physical issue would be helpful in successfully equipping the caregiver to deliver daily dental hygiene. Hands-on training also allowed me to modify any technique issues or answer the caregivers' questions. 
I intended to videotape each session with both the adult with IDD and caregiver to aid in the data collection. The use of video would help verify the consistency of the training sessions' delivery and content. However, the camera I used allowed for only a 30-minute recording and did not allow me to record entire training sessions. Often, during the follow-up visits, some adults with IDD were eating dinner, being bathed, or in bed asleep. So, the actual taping of the adults with IDD was not consistently performed as I intended. This was largely due to the delay of the pilot study for a year. By the time the study began, I was working full time. My schedule was not as flexible as the schedules for those who were in the study and not employed full time elsewhere. In the next study, a more flexible schedule for the dental hygienist will be necessary to provide more consistent videotaping of data.

I encountered adults with IDD and caregivers who did not want to be filmed. Each adult with IDD and caregiver had the option to be filmed or not to be filmed during the initial consenting process. So, some participants were not filmed. Videotaping proved challenging in one instance: an adult with IDD who was participating in the study refused to leave his room when he saw me videotaping the hands-on session with the caregiver. He did not understand I would remove the camera for his part of the training. Another instance occurred during the training of three caregivers. During the videotaping, one caregiver who did not want to be taped did not speak much until the camera was turned off. 


\section{FOLLOW-UP VISITS}

Unlike the initial training visits, the follow-up visits were not scheduled with all caregivers present. Follow-up appointments for each caregiver were made in advance to coincide with their shifts. Often, this meant two to three trips to each home. Some caregivers worked weekends, morning, evening shifts, or some combination of these. Follow-up visits were not scheduled together because of caregivers not wanting to report to work on their day off or for other personal reasons. There was resistance even when scheduling the initial training together. At the follow-up visits, my protocol was to review the current Oral Hygiene Plan with the caregivers to see what was working and what was not working. At that time, I modified any needed hygiene goals to better suit the needs of each adult with IDD. I wanted to disclose the adults with IDD and review the oral hygiene routine at each visit. I also videotaped these sessions, if applicable. These visits were typically about 30 to 45 minutes, depending on how much I could do during the visit.

Hands-on oral hygiene was not regularly done during follow-up visits. Often, the caregivers delayed having me to the home until after their "busy time" of the day. The adults with IDD attended a day program from about 6 to 7 a.m. until 4 or 5 p.m. They usually arrived home around 4:30 or 5:00 p.m., which is the same time the caregivers arrived to start their shifts. Each home had up to three residents. This made evenings (from about 5 p.m. to bedtime) quite busy in the home. The job of this organization's caregivers was to prepare dinner for up to three adults with IDD, clean up from dinner, give out medications and bath and 
dress the adults with IDD. Depending on the home, this was a labor-intensive process for the caregivers and the adults with IDD alike.

Because of the chaos during the evenings (between arriving home and bedtime), I often arrived at the house when the adults with IDD were eating dinner or in bed. This proved to be a challenge. It did not allow me to do much, if any, hands-on training with the adults with IDD during the follow-up visits. I was unable to verify how well the hygiene plan was working for each adult with IDD by not being able to work with them. I had to rely on the caregiver's feedback about what was working and what was not. Nevertheless, because these times were quieter, they offered one benefit: I could focus on the caregivers' questions, the paperwork, and updating the Oral Health Plan.

\section{THE CAREGIVER STAFF}

During the pilot study, I selected two shifts—4 p.m. to midnight and weekends-during which I worked with caregivers. There also was a midnight to

8 a.m. shift during which I did no training because most adults with IDD would be asleep during these hours. Also, these caregivers told me that the hectic morning routine would prevent them from completing oral hygiene on the adults with IDD. The adults with IDD needed to be up around 5 a.m., given medicines, bathed, and dressed so they were ready for their pick up times for transport to the day programs they attended. Depending on the number of adults with IDD in the home and the severity of their disability, this could prove to be a difficult process for the caregivers. 


\section{CHALLENGES WITH CAREGIVER STAFF}

Some of the caregivers, though seemingly interested during the initial training, were not as interested during the follow-up visits. They seemed unconcerned about the dental or overall health improvement of the adult with IDD for whom they were caring. Although they were told about the oral hygiene process, systemic links, and overall benefits of helping with dental hygiene, they did not see it as a necessary step in their routine standard of care. One caregiver never asked any questions or voiced any concerns about the adults with IDD. He just repeatedly asked about when he was to be paid and when the study would end so he could discontinue the oral health care. Another caregiver stated that she did not like dealing with saliva. She did not help during the training and follow-up sessions unless I asked her directly to do so. Changing the mindset of the caregiver regarding dental hygiene was a huge challenge in this pilot study.

At follow-up visits, I left just enough disclosing solution to be used until my next visit. Often, I found little to no disclosing swabs had been used since my last visit. I asked the caregivers if they were using the swabs DAILY, and they said yes—but that was clearly not the case.

I left the Oral Health Plan in the home for the caregivers to reference if they forgot any of the hygiene needs of the adults with IDD. At each home visit, I discussed any problems or concerns about the hygiene goal sheets. On almost all of the Oral Health Plans, I marked that the caregiver should provide daily help with oral hygiene. Yet, when I revisited the homes, I was told, "They do a good job themselves, I don't need to help." I used this as a learning experience and 
disclosed to the adult with IDD, if able, in the presence of the caregiver, that even though the adult with IDD was going through the motions of brushing, it was not effective brushing.

I had no prior knowledge of the very high turnover rate in the organization I worked with during the pilot study. This proved to be very costly for me regarding time and training. I had to call or text each caregiver multiple times before I received a response. Sometimes, I would schedule a follow-up visit with a caregiver, and when I arrived, the caregiver was no longer working for the company or had switched homes. I was never notified of any staff changes by the area supervisors or house managers.

In one instance, I had a pre-test home scheduled for initial training with three caregivers. One of the caregivers had called her supervisor to report being sick, but she did not let me know she was not coming in. When I arrived at the home, the house manager for the sick caregiver was working her shift. Another caregiver was no longer working there, and the third was on her way. The house manager was unaware that I was scheduled to do training that evening. Because the initial training is so involved, I had to reschedule it.

So, for this particular meeting I had worked to coordinate six people's schedules, confirmed meeting times, and showed up on time, only to have the training fall through. Consistent communication from caregivers, house managers, and supervisors was a challenge during this pilot study. Having more internal support from the company would greatly help in any future intervention study. 
CHAPTER III

RESULTS

\section{INTERVENTION IMPLEMENTATION QUALITY}

Aim 2: Assess the quality of implementation of the oral health intervention strategy.

2.1 What is the level of implementation quality as measured by dosage, fidelity, and caregiver reactions?

Regarding the intervention process data, most of the caregivers (20 of 21) participated in the didactic training and assessment and 19 of 21 caregivers participated in the demonstration training and assessment. The majority of the caregivers (16) also participated in the two coaching sessions and the assessments. Further, 15 caregivers participated in seven of the eleven training videos in the group home setting. The response rates varied from $71 \%$ to $90 \%$.

Intervention Processes. These measures pertain to the implementation quality of the intervention and included intervention dosage, implementation fidelity (adherence), and participant reactions relating to the intervention.

The key points of the oral health prevention strategy components were used to create Intervention Dosage and Implementation Fidelity measures for the 
initial session (didactic and observational learning components) and the subsequent reinforcement (coaching component). Dosage measured whether caregivers were present for the entire session, part of the session or not present. Fidelity (adherence) measured whether key points were completely covered or partially covered/not covered. I video recorded and PIRE staff coded observational evaluation data for didactic and in-home training and coaching sessions. I also completed the Process Training forms during and immediately after the sessions. The actual measures were the percentage of caregivers' dosage and fidelity. Measures for each of the four components of the oral health strategy are described below.

Intervention component - Planned Action: The Behavioral Contract briefing was included in the PowerPoint presentation that was narrated by Dr. Binkley and made into a DVD that was played in the group homes on a combo TV/DVD player. At the end of the didactic session and before the observational learning, I again reviewed the contract with the caregivers and they were asked to sign and date the contract. Dosage was the percentage of caregivers who attended the briefing and signed the contract. Fidelity was determined by the percentage of caregivers who completed the contract. Action planning dosage was measured as the percentage of caregivers who fully or partially completed oral health care plans for the adults with IDD. Fidelity for action planning was measured as the percentage of oral health plans that the caregivers updated during the coaching sessions. 
Intervention component - Capacity Building: Dosage was measured by the percentage of caregivers who fully, partially, or did not participate in the initial in-home training that consisted of the didactic (PowerPoint on DVD and video) training, observational learning with demonstrations on a manikin/Dentoform, and observational learning with demonstrations and caregiver participation with me and one of the adults with IDD who resided in the home. Fidelity of the capacity component of the intervention was measured as the percentage of caregivers who completely, partially, or did not receive all key points as documented on the Training Process forms.

Intervention component - Environmental/Behavioral Adaptation: Dosage was measured by the percentage of caregivers who fully, partially, or did not participate in the session where I explained and demonstrated various dental devices including specialized tooth brushes, floss aids, mouth props, various tooth pastes, and mouth rinses. Similarly, dosage was measured the same way in the behavioral strategies portion of the session where desensitization, shaping, reinforcement, and stabilization of the individual's head were covered. Fidelity for the dental devices and behavioral strategies was determined by the percentage of caregivers who received all the key points, partially received the key points, or did not receive any key points.

Intervention component - Reinforcement: I returned to the group homes twice after the initial in-home training to meet with the caregivers and adults with IDD to provide coaching including reviewing and updating the oral health care plans. Dosage for the coaching sessions was measured by the percentage of 
caregivers who had one, two, or no coaching events. Fidelity of the coaching was measured by the percentage of caregivers who completely, partially, or did not receive information about all key points as documented on the Coaching Process forms.

Caregiver Reactions. There were two caregiver reaction surveys. The first reaction survey was administered immediately after the initial in-home training session and asked questions regarding the behavioral contract quality, quality of the in-home training, quality of the training materials, and quality of the in-home training demonstrations, with response options of excellent, good, fair, or poor. The first survey also asked questions about the usefulness of the training on dental devices and behavioral strategies with response options of not at all useful, somewhat useful, and useful. The second reaction survey was administered after the last reinforcement/coaching session as part of the Caregiver SelfAdministered Questionnaire. I asked questions about the reaction to the coaching sessions with response options of very helpful, somewhat helpful, not very helpful, and not at all helpful. The caregivers were also asked about the overall training usefulness with response options of not at all useful, somewhat useful, or useful.

Table 2 presents the level of dosage and fidelity by key oral health strategy elements by intervention components. Level is measured both by percentage and counts of participation. Level of dosage is high across nearly all key elements of my strategy's implementation ranging from $86 \%$ to $95 \%$. Lower participation in the coaching component $(71 \%)$ suggests that special attention 
should be given to coaching participation in a larger study. Similarly,

implementation fidelity is high ranging from $81 \%$ to $90 \%$. Implementation of the

behavioral contract and implementing the observational learning elements as

designed was fair with $71 \%$ and $76 \%$ respectively.

Table 2.

Implementation Quality (Dosage \& Fidelity) by Key Elements of the Oral Health

Strategy

\begin{tabular}{|c|c|c|}
\hline Intervention Component & Dosage & Fidelity (Adherence) \\
\hline \multicolumn{3}{|l|}{ Planned Action } \\
\hline Behavioral Contract & $\begin{array}{l}-95 \% \text { (20 of } 21) \text { CG } \\
\text { attended briefing }\end{array}$ & - $71 \%$ (15 of 21 ) of CG completed contract \\
\hline $\begin{array}{l}\text { Action Planning } \\
\text { (OH action plan) }\end{array}$ & $\begin{array}{l}\text { - 95\% (20 of 21) CG } \\
\text { completed baseline oral } \\
\text { health plan }\end{array}$ & $\begin{array}{l}\text { - } 71 \% \text { (15 of } 21) \text { of CG updated } 2 \text { oral health } \\
\text { plans } \\
-9 \%(2 \text { of } 21) \text { of } C G \text { updated } 1 \text { oral health plan }\end{array}$ \\
\hline \multicolumn{3}{|l|}{ Capacity Building } \\
\hline $\begin{array}{l}\text { Didactic Training } \\
\text { (100\% of key points } \\
\text { completely covered in } \\
\text { PowerPoint and video) }\end{array}$ & $\begin{array}{l}-86 \%(18 \text { of } 21) \text { of } C G \\
\text { attended entire session } \\
-9 \%(2 \text { of } 21) \text { of CG } \\
\text { attended part of session }\end{array}$ & $\begin{array}{l}\text { - } 86 \% \text { (18 of } 21) \text { of CG completely received all } \\
\text { key points } \\
-9 \%(2 \text { of } 21) \text { of CG partially received all key } \\
\text { points }\end{array}$ \\
\hline $\begin{array}{l}\text { Observational Learning } \\
\text { (Dentoform) } \\
\text { (100\% of oral hygiene } \\
\text { practices key points } \\
\text { completely covered) }\end{array}$ & $\begin{array}{l}-86 \% \text { (18 of } 21) \text { of } C G \\
\text { attended entire session } \\
-9 \%(2 \text { of } 21) \text { attended part } \\
\text { of session }\end{array}$ & $\begin{array}{l}\text { - } 86 \% \text { (18 of } 21) \text { of CG completely received all } \\
\text { key points } \\
-9 \%(2 \text { of } 21) \text { of CG partially received all key } \\
\text { points }\end{array}$ \\
\hline $\begin{array}{l}\text { Observation Learning } \\
\text { (OH Demo with Resident) }\end{array}$ & $\begin{array}{l}-86 \%(18 \text { of } 21) \text { of } C G \\
\text { attended entire session } \\
-9 \%(2 \text { of } 21) \text { of } C G \\
\text { attended part of session }\end{array}$ & $\begin{array}{l}-76 \% \text { (16 of } 21) \text { of CG received all key points } \\
-19 \%(4 \text { of } 21 \text { ) of CG received partial key } \\
\text { points }\end{array}$ \\
\hline \multicolumn{3}{|c|}{ Environmental/Behavioral Adaptation } \\
\hline $\begin{array}{l}\text { Dental Devices } \\
\text { (100\% of key points } \\
\text { completely covered) }\end{array}$ & $\begin{array}{l}\text { - } 90 \% \text { ( } 19 \text { of } 21) \text { of } C G \\
\text { attended entire session } \\
-10 \% \text { ( } 2 \text { of } 21) \text { of } C G \\
\text { attended part of session }\end{array}$ & $\begin{array}{l}\text { - 90\% (19 of } 21 \text { ) of CG receive all key points } \\
\text { key points regarding } 4 \text { dental devices }\end{array}$ \\
\hline $\begin{array}{l}\text { Behavioral Strategies } \\
\text { ( } 90 \% \text { of behavioral } \\
\text { adaptation key points } \\
\text { completely covered) }\end{array}$ & $\begin{array}{l}\text { - } 90 \% \text { (19 of } 21) \text { of CG } \\
\text { attended entire session } \\
\text { - } 10 \% \text { ( } 2 \text { of } 21) \text { of CG } \\
\text { attended part of session }\end{array}$ & $\begin{array}{l}\text { - 90\% (19 of 21) of CG received all key points } \\
\text { regarding behavioral strategies }\end{array}$ \\
\hline \multicolumn{3}{|l|}{ Reinforcement } \\
\hline Coaching & $\begin{array}{l}-71 \% \text { ( } 15 \text { of } 21) \text { of CG had } \\
2 \text { coaching events } \\
-9 \%(2 \text { of } 21) \text { of CG had } 1 \\
\text { coaching event }\end{array}$ & $\begin{array}{l}-81 \% \text { (17 of } 21 \text { ) of CG reviewed achievement } \\
\text { of oral health goals during coaching visits }\end{array}$ \\
\hline
\end{tabular}

Note: $\mathrm{CG}=$ caregivers; $\mathrm{OH}=$ oral health . 


\section{PARTICIPANT REACTION}

The data in Table 3 were collected as part of the post-assessment, and therefore, only $76 \%$ (i.e., 16 of 21 caregivers) responded to the self-administered questionnaire). It was found that the caregivers' reactions to the training were all high (all means were larger than 2.53 on a 0 to 3 response scale).

Table 3.

Average Caregiver Reaction to Key Elements of the Oral Health Strategy $(\mathrm{N}=16)$

\begin{tabular}{|lc|}
\hline Key Elements by Intervention Component & Average \\
\hline Planned Action & \\
\hline Behavioral Contract Quality & 2.56 \\
\hline Capacity Building & 2.78 \\
\hline Quality Didactic Training & 2.83 \\
Quality In-Home Training Demonstrations & 2.80 \\
Quality Training Materials & 2.84 \\
Overall Usefulness of Training & \\
\hline Environmental/Behavioral Adaptation & 2.54 \\
\hline Dental Device Use & 2.61 \\
\hline Behavioral (Cooperation) Strategy Use & \\
\hline Reinforcement & 2.89 \\
\hline Coaching
\end{tabular}

Note: Scores range from $0-3$ where 3 is a more desirable rating.

\section{CHANGE IN OUTCOMES}

When I examined change over time on the outcomes, I found statistically significant improvements over time on both of the direct outcomes: the O'Leary plaque score (100\% to $49 \%)$ and the Oral Assessment Guide (1.60 to 1.78). There were statistically significant improvements on two of the five oral health practices outcomes (\% disclosed $-11 \%$ to $58 \%$ and $\%$ disclosed $-14 \%$ to $44 \%$ ), as well as the summary score for oral health practices. For oral health support, the only significant improvement of 5 was in the area of support, which increased from $77 \%$ to $94 \%$ in the number of residents supported. 


\section{CHAPTER IV}

\section{DISCUSSION}

The results of the implementation of the oral health intervention suggest that delivering it to this population with quality can be challenging. Providing dental knowledge and showing its importance is essential to delivering a standard quality of care. An intervention needs training and education, physical and behavioral tools, strong partner organizational support, and caregivers who are motivated to improve the oral health of the adults with IDD in their care.

This pilot study focused on the dental hygiene of only the adults with IDD within one group home organization. Other investigators have also endeavored to improve the oral health of this population. The aim of the Faulks and Hannequin study(11) was to educate and to determine how the role of caregiver affected the adults with IDD in their care. Faulks and Hannequin agreed with the findings of other researchers that the lack of oral hygiene, patient medications, and proper function are all important for a patient to have good oral health.(1724) Unlike my study, the adults with IDD had a full treatment plan to fix periodontal issues (with cleaning or scaling and root planing), restorations placed to remove cavities, and extractions and/or tooth replacement, if needed. I did not 
collaborate with a dentist to fix existing dental health issues as Faulks and Hannequin did in their study.

Faulks and Hannequin worked with both home and day program caregivers throughout the entire study. Implementing an Oral Health Care Plan in both the day program and the group home settings would increase daily dental hygiene for adults with IDD. In my pilot study, I primarily worked on the adults with IDD at the group home setting. Toward the end of my study, I did training for a couple of days with one caregiver and the adults with IDD in their day program she supervised. This dual education method (day program and group homes), as was done in the Faulks and Hannequin study, allowed for dental hygiene to be performed multiple times a day versus once a day at the group home. As the atmosphere of the day program allowed me more time during the initial training to be uninterrupted, I had more quality time with the caregivers. One caregiver was happy to help with daily oral hygiene and was excited to see her progress during my short training sessions. This twofold approach may be better for conducting a larger study in the future.

Faulks and Hannequin also had a larger number of people involved in their study. They had 67 adults with IDD and 69 caregivers located at three different facilities that participated in the study. Their education focused on the attitudes and habits of the caregivers, which, in turn would directly improve the oral health of the adults with IDD. They not only checked the hygiene of the adults with IDD, but also of the caregivers themselves. Faulks and Hannequin found that the caregivers always had cleaner teeth than their adults with IDD. 
They attributed this finding to the difficulty of performing oral hygiene on the adults with IDD. Nevertheless, they concluded that caregivers did understand the problems and pain that are associated with not doing daily dental hygiene. The caregivers understand that the lack of dental care can lead to many dental problems and pain in their own mouths yet they frequently failed to perform adequate oral hygiene for their adults with IDD. This is due to the fact that the act of performing oral hygiene on a patient with IDD is not as easy as it is on a lay person. There are various physical and or mental capacities to work around that makes it difficult. This difficulty of performing oral care often leads to the caregiver not performing proper dental care at all on their adults with IDD.

Often caregivers of adults with IDD feel overburdened in their daily duties. In both my study and the Faulks and Hannequin study, this was a common finding. Implementing a new dental hygiene protocol seemed to add to the burden of the caregivers' daily duties. There was habitual turnover and many overworked staff due to staffing issues in the Faulks and Hannequin study.(23, 25-27) This was a common issue with the caregivers I worked with as well. In both my study and the Faulks and Hannequin study, the group home caregivers apparently lacked medical training. Although they were given oral hygiene training and shown the importance of oral care to prevent disease and problems, they still felt like the mouth was a more "private" place. $(28,29)$ Caregivers did not like the gingival bleeding, heavy plaque, bad breath, or saliva they encountered in helping with hygiene. This proved to be a comparable issue for caregivers participating in my study. 
Glassman and Miller conducted a study similar to my pilot study in 2006.(12) They realized that group home settings were becoming the norm. This was due to adults with IDD being moved from institutions into group homes, a movement that began in the 1970s. $(30,31)$ The Glassman and Miller trainings concentrated on "Overcoming Obstacles to Dental Health,"(32) as I did. However, they used both of the videos and the entire workbook. I was unable to have extended initial training sessions that afforded me the time to do the entire workbook and both videos.

Glassman's and Miller's initial training consisted of a pretest to determine the dental knowledge of the caregivers. Then, they completed the training in two 3-hour classes per facility. These 3-hour training sessions consisted of one video and six chapters in the workbook at each session and completing the entire course in two sessions. At the completion of the second session, a posttest was administered. In contrast, I used only one of the two videos on "Overcoming Obstacles."(32) I focused on the information that would give the caregivers basic "how-to" skills that could be used within their group home settings.

The caregivers in the Glassman and Miller study received no "hands-on" training with a typodont, brushing skills, or direct interaction with adults with IDD. I feel that the hands-on training is an integral part of the learning process. Providing "hands-on" training allowed me to broaden my scope on the various learning skills of each caregiver. It allowed me to address with the caregivers the specific physical, behavioral, or mental issues that could arise for the adults with IDD under their care. 
One of the biggest obstacles in the Glassman and Miller study was caregiver turnover.(33) As mentioned previously, this was also a challenge in the Faulks and Hannequin study $(23,25-27)$ and in my study. Apparently, in many areas of patient care (elderly, adults with IDD, etc.), caregivers suffer burn out due to the demands of the job. Finding a partner organization that values education and encourages and values their staff would be beneficial as a partner organization for a larger study.

Van der Putten and colleagues(34) conducted a study in the Netherlands and Belgium where the ailing elderly population is put into group homes for daily care. $(35,36)$ They rely heavily on nurses and/or medical assistants to take care of their daily needs, $(37,38)$ just as an adult with IDD does. For this reason, I'm paralleling the study to mine because they both fall under the same category of specialized dentistry.

Van der Putten's study, along with my own study, stressed the importance of good oral hygiene due to the systemic links periodontal disease and mouth infection has on the whole body. $(39,40)$ The systemic link concept was not widely discussed with the caregivers in my study. Not knowing about this link often means that oral hygiene is overlooked.(42) Having caregivers educated on the importance of proper daily oral hygiene is pivotal in the success of implementing an oral hygiene protocol.(43) I found this to be the case during my pilot test.

The adults with IDD, just like the elderly population in van der Putten's study, struggle with long lists of medications that adversely affect the mouth. 
Medications can cause increased or decreased salivation, leading to cavities; xerostomia (dry mouth that increases cavities, problems with mastication, and swallowing); and increased bleeding of the gingival tissue and inflammation.(41)

In van der Putten's study and my pilot test, it was evident that the cooperation of adults with IDD was a huge factor in the caregivers' ability to provide care.(44) In my study, I often heard things like, "he won't let me brush his teeth" or "how do you have her sit still while you are working." Caregivers had no additional tools other than what the adult with IDD already used for daily oral hygiene. I supplied physical tools, such as disclosing solution; regular, electric, and Collis toothbrushes (cleans multiple surfaces at a time); various flavored toothpastes; mouth props; and mirrors. More importantly, I showed behavioral techniques to the caregivers to aid them in performing oral care. These gave tangible tools to the caregivers to help them eliminate mental and/or physical boundaries to providing daily dental care.

Van der Putten's study showed the importance of "in-house" support with supervisors and head nurses stressing the increased priority of oral care for their residents. $(45,46)$ During my pilot study, I seemed to have full support from upper management; however, they failed to inform middle and lower management of their participation. Consequently, I encountered barriers and delays.

Van der Putten's study expanded the oral care training to include an "inhouse supervisor" for a ward of patients. The supervisor elected a Ward Oral health care Organizer (WOO). The "In-house supervisors" in the study rigorously trained the WOOs and caregivers with all the knowledge they needed on why 
and how oral hygiene was important. The WOOs were in charge of on-site training for their nurses and nurses' aides, using their knowledge of the techniques and the process. They also acted to assist and support their staff with elderly individual and the hygiene protocols.

There is still a great need to implement solid dental education and a dental hygiene protocol in hospitals and group homes.(47-49) van der Putten and colleagues used a protocol developed in 2007, called Oral health care in (residential) care homes for elderly people. It was in alignment with Dutch guidelines called Appraisal of Guidelines Research and Evaluation Instrument (AGREE).(50) It details "all aspects of good oral health and oral care, presents the methods and skills needed for providing oral health care to residents, and presents effective oral health and oral hygiene assessment tools. The ultimate objective of the guideline is to improve the oral health of residents." $(34$, p. 2)

Almomani et al.(51) conducted a study that was less of an intervention but more a modified approach to learning oral hygiene for patients with psychiatric issues, such as schizophrenia and schizoaffective disorders (e.g., bipolar disorder and depression). They placed more emphasis on lifestyle change and behavioral changes need to be implemented into a modified dental health education program.(52-56) As with any change in lifestyle, education must be at the patients' level to aid in that change. Just like with any other specialty group (elderly, IDD, psychiatric), an oral health education plan has to be modified to accommodate for various mental, behavioral, or psychological complications.(58) 
The similarity I draw from this article, which parallels my research, is the typically lengthy list of medications that have the same negative oral side effects, whether administered to patients who are older or patients with IDD. Xerostomia, for example, can increase risk of cavities due to no saliva to buffer acid, which can be problematic. (57) Sometimes an individual with dry mouth will suck on sugary candy or chewing gum, which can also increase the risk of decay. $(58,59)$ Jablonski et al.(60) conducted a study based on the rationale that Care Resistant Behavior (CRB) can be a large barrier to receiving routine oral health care(61) in nursing homes $(\mathrm{NH})$. They postulated that because of how the different areas of the brain work in $\mathrm{NH}$ patients, they perceive regular nurse aid encounters as threatening. $(62,63)$ Similarly, adults with IDD may be threatened by a caregiver encounter to perform dental hygiene.

For their study, Jablonski et al. designed an intervention that would reduce the CRBs in NH patients with moderate to severe dementia. They also wanted to see if the reduced CRBs would allow more routine dental care to be performed, which in turn would increase the patient's dental health. They devised an intervention plan called MOUTh (Managing Oral hygiene Using Threat reduction), the elements of which they listed in a table (Table 1, p. 79), along with a description of the Strategy and Rationale for some of the modifications. For example, Strategy \#1 is "Approach the resident at eye level and within his or her visual field, and Rationale \#1 is "Towering over a resident may invoke a threat response and CBRs." 
The Jablonski et al. study included oral health protocols, along with morning and night routines. The process took about 10 minutes at the start of the study. With consistent practice, that time was reduced to about 5 minutes. They found that $90 \%$ of the cooperative patients had "adequate" oral hygiene and that only $10 \%$ of the uncooperative patients had adequate oral hygiene.(64) Managing the CBR of the individual receiving medical or dental care proved to be very important. Giving caregivers proper behavioral tools is essential to increasing the overall health of adults with IDD. Attention to this key challenge will aid in the success of any health intervention.

In conclusion, the studies cited above show that key elements are often left out of an intervention. This deficiency can cause an imbalance that will make an intervention less impactful or a failure. The findings from my pilot study have allowed me to iron out organizational, data collection, and equipment issues. This is vital information that can be used in a larger randomized controlled intervention study in the future. 


\section{CHAPTER V \\ SUMMARY AND CONCLUSIONS}

My pilot test was necessary to develop, analyze, and refine the initial oral health intervention approach. The data from my pilot test showed a marked increase in the improvement of oral health and caregiver participation in dental hygiene with the adults with IDD who reside in group homes. Further, I had moderate to high quality implementation as measured by dosage, fidelity and caregiver reactions. These high marks occurred even though my study was only a pre-post evaluation with no control group.

During this pilot study, I learned many lessons that will benefit others in implementing a larger randomized controlled trial (RCT) in the future. I found it is imperative to have strong working relationships with the management and staff of my partner organizations who will commit to fully participate in a study. Some of these commitments would be notification of staff turnover and new hires that would enable our team to consent and train replacements more quickly, implement internal policies that are geared toward improving the oral health of adults with IDD, modify the questionnaires to caregivers to lessen the "datacollection burden," and replace or revise some of the measures to better address self-efficacy and oral health quality of life. Finally, to ensure implementation 
fidelity, obtaining better equipment to videotape the intervention activities is imperative.

In sum, despite my small sample size for the pilot study and the difficulties I encountered, I feel the outcome results show my oral health strategy warrants a chance to be tested in a larger randomized controlled trial. I showed high levels of quality of the strategy's implementation dosage, fidelity, and caregiver reaction to participation. I plan to incorporate a final Study Protocol and Manual of Operation Procedures that will allow others to be more effective in a larger study. 


\section{REFERENCES}

1. Stanfield M, Scully C, Davison MF, Porter S. Oral healthcare of clients with learning disability: changes following relocation from hospital to community. Br Dent J. 2003;194(5):271-7; discussion 62.

2. Larson SA, Scott N, Salmi P, Lakin KC. Changes in number and characteristics of people living in state institutions, 1977-2008. Intellect Dev Disabil. 2009;47(4):329-33.

3. Lewis MA, Lewis CE, Leake B, King BH, Lindemann R. The quality of health care for adults with developmental disabilities. Public Health Rep. 2002;117(2):174-84. PMCID: 1497422.

4. Bershadsky J, Kane RL. Place of residence affects routine dental care in the intellectually and developmentally disabled adult population on Medicaid. Health Serv Res. 2010;45(5 Pt 1):1376-89.

5. Anders PL, Davis EL. Oral health of patients with intellectual disabilities: a systematic review. Spec Care Dentist. 2010;30(3):110-7.

6. Lindemann R, Zaschel-Grob D, Opp S, Lewis MA, Lewis C. Oral health status of adults from a California regional center for developmental disabilities. Spec Care Dentist. 2001;21(1):9-14.

7. Pezzementi ML, Fisher MA. Oral health status of people with intellectual disabilities in the southeastern United States. J Am Dent Assoc. 2005;136(7):903-12.

8. Reid BC, Chenette R, Macek MD. Prevalence and predictors of untreated caries and oral pain among Special Olympic athletes. Spec Care Dentist. 2003;23(4):139-42.

9. Binkley CJ, Haugh GS, Kitchens DH, Wallace DL, Sessler DI. Oral microbial and respiratory status of persons with mental retardation/intellectual and developmental disability: an observational cohort study. Oral Surg Oral Med Oral Pathol Oral Radiol Endod. 2009;108(5):722-31. PMCID: 2763931.

10. Avenali L, Guerra F, Cipriano L, Corridore D, Ottolenghi L. Disabled patients and oral health in Rome, Italy: long-term evaluation of educational initiatives. Ann Stomatol (Roma). 2011;2(3-4):25-30. PMCID: 3314314. 
11. Faulks D, Hennequin M. Evaluation of a long-term oral health program by carers of children and adults with intellectual disabilities. Spec Care Dentist. 2000;20(5):199-208.

12. Glassman $\mathrm{P}$, Miller $\mathrm{CE}$. Effect of preventive dentistry training program for caregivers in community facilities on caregiver and client behavior and client oral hygiene. N Y State Dent J. 2006;72(2):38-46.

13. Lange B, Cook C, Dunning D, Froeschle ML, Kent D. Improving the oral hygiene of institutionalized mentally retarded clients. J Dent Hyg. 2000;74(3):205-9.

14. Fickert NA, Ross D. Effectiveness of a caregiver education program on providing oral care to individuals with intellectual and developmental disabilities. Intellect Dev Disabil. 2012;50(3):219-32.

15. Knazan YL. Application of PRECEDE to dental health promotion for a Canadian well-elderly population. Gerodontics. 1986;2(5):180-5.

16. Sato K, Oda M. Analysis of the factors that affect dental health behaviour and attendance at scheduled dental check-ups using the PRECEDE-PROCEED Model. Acta Med Okayama. 2011;65(2):71-80.

17. Maclaurin ET, Shaw L, Foster TD. Dental caries and periodontal disease in children with Down's syndrome and other mentally handicapping conditions. J Paediatr Dent. 1985;1(1):15-9.

18. Nunn JH. The dental health of mentally and physically handicapped children: a review of the literature. Community Dent Health. 1987;4(2):157-68.

19. O'Donnell JP, Cohn MM, Sr. Dental care for the institutionalized retarded individual. J Pedod. 1984;9(1):3-38.

20. Ohmori I, Awaya S, Ishikawa F. Dental care for severely handicapped children. Int Dent J. 1981;31(3):177-84.

21. Shapira J, Efrat J, Berkey D, Mann J. Dental health profile of a population with mental retardation in Israel. Spec Care Dentist. 1998;18(4):149-55.

22. Shaw MJ, Shaw L, Foster TD. The oral health in different groups of adults with mental handicaps attending Birmingham (UK) adult training centres. Community Dent Health. 1990;7(2):135-41.

23. Stabholz A, Shapira J, Shur D, Friedman M, Guberman R, Sela MN. Local application of sustained-release delivery system of chlorhexidine in Down's syndrome population. Clin Prev Dent. 1991;13(5):9-14.

24. Vigild M. Periodontal conditions in mentally retarded children. Community Dent Oral Epidemiol. 1985;13(3):180-2.

25. Johnson TE, Lange BM. Preferences for an influences on oral health prevention: perceptions of directors of nursing. Spec Care Dentist. 1999;19(4):173-80. 
26. MacEntee MI, Thorne S, Kazanjian A. Conflicting priorities: oral health in long-term care. Spec Care Dentist. 1999;19(4):164-72.

27. Weeks JC, Fiske J. Oral care of people with disability: a qualitative exploration of the views of nursing staff. Gerodontology. 1994;11(1):13-7.

28. Erickson L. Oral health promotion and prevention for older adults. Dent Clin North Am. 1997;41(4):727-50.

29. Ritoli E, Katz R, Stokes E. Oral hygiene vs. other body care services: a comparison of nurse's aides beliefs and attitudes (abstract). J Dent Res. 1990(69 (special issue)):331.

30. Lakin K, Bruininks R. Social integration of developmentally disabled persons. Lakin K, Bruininks R, editors. Baltimore: Paul H. Brookes Publishing Co.; 1985.

31. Bureau of the Census U. Disabilities affect one-fifth of all Americans. Census brief, CENBR/97-5. In: U.S Department of Commerce EaSA, editor. Washington, DC: U.S. Government; 1997.

32. Miller C, Glassman P, Wozniak T, Gillien N. Overcoming Obstacles to Dental Health - A Training Program For Caregivers of People with Disabilities 1998.

33. Thornton JB, al-Zahid S, Campbell VA, Marchetti A, Bradley EL, Jr. Oral hygiene levels and periodontal disease prevalence among residents with mental retardation at various residential settings. Spec Care Dentist. 1989;9(6):186-90.

34. van der Putten GJ, De Visschere L, Schols J, de Baat C, Vanobbergen J. Supervised versus non-supervised implementation of an oral health care guideline in (residential) care homes: a cluster randomized controlled clinical trial. BMC Oral Health. 2010;10:17. PMCID: 2912776.

35. Rothera I, Jones R, Harwood R, Avery A, Waite J. Health status and assessed need for a cohort of older people admitted to nursing and residential homes. Age Ageing. 2003;32(3):303-9.

36. Schols JM, Crebolder HF, van Weel C. Nursing home and nursing home physician: the Dutch experience. J Am Med Dir Assoc. 2004;5(3):207-12.

37. Gil-Montoya JA, de Mello AL, Cardenas CB, Lopez IG. Oral health protocol for the dependent institutionalized elderly. Geriatr Nurs. 2006;27(2):95101.

38. Stein PS, Henry RG. Poor oral hygiene in long-term care. Am J Nurs. 2009;109(6):44-50; quiz 1.

39. Rautemaa R, Lauhio A, Cullinan MP, Seymour GJ. Oral infections and systemic disease--an emerging problem in medicine. Clin Microbiol Infect. 2007;13(11):1041-7. 
40. Seymour GJ, Ford P, Cullinan M, Leishman S, Yamazaki K. Relationship between periodontal infections and systemic disease. Clin Microbiol Infect. 2007;14 (Suppl 4):3-10.

41. Ciancio SG. Medications' impact on oral health. J Am Dent Assoc. 2004;135(10):1440-8; quiz 68-9.

42. Murray PE, Ede-Nichols D, Garcia-Godoy F. Oral health in Florida nursing homes. Int J Dent Hyg. 2006;4(4):198-203.

43. Costello T, Coyne I. Nurses' knowledge of mouth care practices. $\mathrm{Br} \mathrm{J}$ Nurs. 2008;17(4):264-8.

44. Coleman $P$, Watson NM. Oral care provided by certified nursing assistants in nursing homes. J Am Geriatr Soc. 2006;54(1):138-43.

45. Chung JP, Mojon P, Budtz-Jorgensen E. Dental care of elderly in nursing homes: perceptions of managers, nurses, and physicians. Spec Care Dentist. 2000;20(1):12-7.

46. Sweeney MP, Williams C, Kennedy C, Macpherson LM, Turner S, Bagg J. Oral health care and status of elderly care home residents in Glasgow. Community Dent Health. 2007;24(1):37-42.

47. McGrath C, Zhang W, Lo EC. A review of the effectiveness of oral health promotion activities among elderly people. Gerodontology. 2009;26(2):85-96.

48. O'Reilly M. Oral care of the critically ill: a review of the literature and guidelines for practice. Aust Crit Care. 2003;16(3):101-10.

49. Vanobbergen JN, De Visschere LM. Factors contributing to the variation in oral hygiene practices and facilities in long-term care institutions for the elderly. Community Dent Health. 2005;22(4):260-5.

50. Collaboration A. Development and validation of an international appraisal instrument for assessing the quality of clinical practice guidelines: the AGREE project. Qual Saf Health Care. 2003;12(1):18-23. PMCID: 1743672.

51. Almomani F, Brown C, Williams KB. The effect of an oral health promotion program for people with psychiatric disabilities. Psychiatr Rehabil J. 2006;29(4):274-81.

52. Friedlander AH, Mahler ME. Major depressive disorder. Psychopathology, medical management and dental implications. J Am Dent Assoc. 2001;132(5):629-38.

53. King KC. The dental care of the psychiatric patient. N Z Dent J. 1998;94(416):72-82.

54. Payne BJ, Locker D. Preventive oral health behaviors in a multi-cultural population: the North York Oral Health Promotion Survey. J Can Dent Assoc. 1994;60(2):129-30, 33-9. 
55. Watt RG. Emerging theories into the social determinants of health: implications for oral health promotion. Community Dent Oral Epidemiol. 2002;30(4):241-7.

56. Williford JW, Muhler JC, Stookey GK. Study demonstrating improved oral health through education. J Am Dent Assoc. 1967;75(4):896-902.

57. Friedlander $\mathrm{AH}$, Liberman RP. Oral health care for the patient with schizophrenia. Spec Care Dentist. 1991;11(5):179-83.

58. Clark DB. Dental care for the psychiatric patient: chronic schizophrenia. J Can Dent Assoc. 1992;58(11):912-6, 9-20.

59. Clark DB. Dental care for the patient with bipolar disorder. J Can Dent Assoc. 2003;69(1):20-4.

60. Jablonski RA, Therrien B, Mahoney EK, Kolanowski A, Gabello M, Brock A. An intervention to reduce care-resistant behavior in persons with dementia during oral hygiene: a pilot study. Spec Care Dentist. 2011;31(3):77-87.

61. Mahoney EK, Hurley AC, Volicer L, Bell M, Gianotis P, Hartshorn M, et al. Development and testing of the Resistiveness to Care Scale. Res Nurs Health. 1999;22(1):27-38.

62. LeDoux J. The emotional brain, fear, and the amygdala. Cell Mol Neurobiol. 2003;23(4-5):727-38.

63. Maren S. Building and burying fear memories in the brain. Neuroscientist. 2005;11(1):89-99.

64. Samson H, Berven L, Strand GV. Long-term effect of an oral healthcare programme on oral hygiene in a nursing home. Eur J Oral Sci. 2009;117(5):575-9. 


\section{CURRICULUM VITAE}

NAME: $\quad$ Brigit Zaksek

ADDRESS: $\quad 1320$ Trinity Park Drive

Louisville, KY 40213

DOB: $\quad$ July 29,1974

EDUCATION

\& TRAINING: $\quad$ B.S., Dental Hygiene

Ohio State University

1992-97

M.S., Oral Biology

University of Louisville

2010-present

\section{EXPERIENCE:}

Dr. Richard Loochtan

Pickerington, Ohio 6/1997-11/97

- Pediatric Dental Hygienist. I performed routine prophylaxis, fluoride, sealants and radiographs on children ages $1+$

Dr. Laury DiMichaelangelo

Columbus, Ohio 11/97-7/98

- General Dental Hygienist. I performed routine prophylaxis, fluoride, sealants radiographs, sealants, scaling \& root planing

Dr. Gerald Kassoy

Bexley, Ohio 6/97-12/99

- Pediatric Dental Hygienist. I performed routine prophylaxis, fluoride, sealants and radiographs on children ages $1+$ 
- Pediatric Dental Hygienist. I performed routine prophylaxis, fluoride, sealants and radiographs on children ages $1+$

- General Dental Hygienist. I performed routine prophylaxis, fluoride, radiographs, sealants, scaling and root planing

- TMJ infrared and tens unit therapy performed on jaw/neck muscles, placement of orthodontic wires, ties and chains

- Completed impressions for study models, trimmed bite guards and other occlusal appliances

\section{Dr. Kristin Medors}

Arlington, Ohio 7/03-6/05

- General Dental Hygienist. I performed routine prophylaxis, fluoride, radiographs, sealants, scaling and root planing

Dr. Dennis Rinaldi

- General Dental Hygienist. I performed routine prophylaxis, fluoride, radiographs, sealants, scaling and root planing

Regency Dental (Dr. Giol and Jaffe)

- General Dental Hygienist. I performed routine prophylaxis, fluoride, radiographs, sealants, scaling and root planing

\section{Mortenson Family Dental L Louisville, Kentucky 8/09-Current}

- General Dental Hygienist. I performed routine prophylaxis, fluoride, radiographs, sealants, scaling and root planing

- Laser Certified for Laser Bacterial Removal and Laser Gingival Currettage 